\title{
Economic Inequality and Nonviolent Protest*
}

\author{
Frederick Solt, University of Iowa
}

\begin{abstract}
Objective. Despite substantial theorizing, the relationship between economic inequality and participation in nonviolent protests has not been satisfactorily examined empirically. Methods. Using multilevel models of data from four waves of the European Social Survey, this article examines whether differences in inequality across countries and over time help explain people's engagement in peaceful protest. Results. It finds that greater inequality reduces protest participation for all those with incomes below the top quintile. Conclusions. This result provides strong support for the relative power theory of political participation; the predictions of grievance and resource theories regarding inequality's effects on protest are not supported.
\end{abstract}

${ }^{*}$ Direct all correspondence to Frederick Solt, Department of Political Science, 341 Schaeffer Hall, University of Iowa, Iowa City, Iowa 52242, <frederick-solt@uiowa.edu>. Replication materials are available at the author's website, <http://myweb.uiowa.edu/fsolt >. 
In recent years, protests against economic inequality have erupted in many countries around the world. Although inequality has been the target of these protests, the broader relationship between inequality and participation in nonviolent protest remains unclear. Does inequality sharpen grievances that motivate more people among the poor to protest (see, e.g., Gurr 1970)? Or does the lopsided distribution of resources provide richer people more - and poorer people less - of what they need to participate in protests (see, e.g., Verba, Schlozman, and Brady 1995)? Or, as recent works on the relative power theory suggest, does inequality shape the political landscape in ways that discourage all but the most well-off from engaging in political activities like protesting (see, e.g., Solt 2008)? Few previous works have investigated this relationship empirically, and those that have studied it reach diverging conclusions.

Using data from four waves of the European Social Survey, this article examines whether and how differences in levels of inequality contribute to variation across countries and over time in people's tendencies to engage in nonviolent political protest. Consistent with the relative power theory, and contradicting the expectations of the grievance and resource theories, it finds that more income inequality is associated with less participation in nonviolent protests among all individuals except those in the highest income quintile. These findings are an important contribution to the understanding of both protest participation and the political effects of economic inequality.

\section{Inequality and Nonviolent Protest}

The relative power theory starts with the proposition that money is a political resource: that is, that it can be used to influence others. Therefore, the theory contends, where the rich are richer relative to the poor, they will also be more powerful relative to the poor (Goodin and Dryzek 1980). In this view, the greater power imbalance that results from higher levels of economic inequality then allows richer individuals not only to prevail more consistently in open debates on issues that divide primarily along income lines, but also to more successfully prevent these issues from reaching the political agenda at all, and even to more thoroughly convince poorer individuals to abandon their preferences on these issues entirely in favor of the positions 
maintained by the rich (Solt 2008, 49). As a result of this rising imbalance in power, while richer individuals will remain somewhat motivated by the issues that divide them, poorer individuals will be more likely to simply withdraw from a political environment that is unresponsive to their needs and desires. Previous research has focused on how the increased relative power of the wealthy that is concomitant with higher levels of income inequality affects participation in elections (see Solt 2008, 2010), but the theory predicts that participation in nonviolent protests should exhibit similar patterns.

Grievance theory provides an opposing argument that maintains that inequality should be associated with more, rather than less, protest activity among those with lower incomes. Relative deprivation — having less than others have - is seen as motivating people to engage in protest activities (see, e.g., Lipsky 1968; Gurr 1970). Because higher levels of economic inequality mean that poorer individuals are even more worse off compared to their prosperous fellow citizens, more inequality should prompt them to be more likely to participate in peaceful protests. For the most well-off, on the other hand, the greater concentration of economic resources in their hands should reduce their grievances and so result in less protest activity among members of this social stratum.

A third perspective on the relationship between inequality and protest is provided by theory that focuses on the role of individuals' resources in their participation. According to this view, belying its common depiction as a 'weapon of the weak,' engaging in protest is a demanding activity, and those with higher incomes are better able to afford its associated costs (e.g., Verba, Schlozman, and Brady 1995, 191). This suggests that, all else equal, as economic inequality increases within a country, relatively poor individuals will have fewer - and relatively rich individuals will have more - of the resources needed to participate in protest activities. As a result, and in direct opposition to the predictions of grievance theory, the resource theory predicts that rising inequality will decrease protest participation among poorer people but increase it among richer people.

It is perhaps worth underscoring that, of these three contending theories, only grievance theory asserts that the economic inequality itself will be the issue that spurs protest participation. Relative power theory maintains only that whatever issues about which richer individuals generally agree will, as inequality 
increases, be more likely to be excluded from the political agenda, regardless of the views of poorer people, discouraging the latter from all forms of political participation, including protest. Resource theory is similarly agnostic as to the content of protest: its focus is instead on whether individuals have the wherewithal to raise their voices on whatever issue they might choose.

In contrast to the extensive body of work on the relationship between economic inequality and political violence (see, e.g., Boix 2008), previous research on inequality and nonviolent protest is scant. What little work has been done, moreover, has arrived at diverging conclusions. Nollert (1995) found that inequality has a positive effect on protest, while Dubrow, Slomczynski, and Tomescu-Dubrow (2008) found the opposite, that inequality has a negative relationship with protest. Balme and Chabanet $(2008,68)$ concluded that inequality bears no important relationship to protest at all. ${ }^{1}$

Besides their contradictory findings, there are several additional aspects of these works that counsel against regarding any of them as conclusive. First, each study examined only a small number of different contexts of economic inequality, between eleven and twenty-six; with so few observations, the instability of the results obtained is not surprising. Second, their models of protest are underspecified: Nollert (1995) and Balme and Chabanet (2008) considered only bivariate relationships between inequality and protest, while the only other aspect of context included in the two-level model presented by Dubrow, Slomczynski, and Tomescu-Dubrow (2008) was whether the country's democracy was only recently established. None assess the plausibly important role of variation in political institutions in encouraging or dampening protest activity, a potentially serious source of spuriousness given arguments linking institutional arrangements to economic inequality (see, e.g., Iversen and Soskice 2006). Third, the measures of protest these works employed are less than fully satisfying. Balme and Chabanet (2008) looked at the average number of protest acts that survey respondents reported they had done; Dubrow, Slomczynski, and Tomescu-Dubrow (2008) examined whether respondents had reported participating in any of a list of three protest activities; and Nollert (1995) investigated only the number of demonstrations. By combining different types of nonviolent protest into a single measure, or considering only one, these studies provide no information on whether inequality has similar effects on the very different activities by which people may engage in peaceful protest. Finally, and 
most importantly, none of these analyses included the interaction between inequality and individual income needed to test the alternate predictions of the relative power, grievance, and resource theories of protest participation.

The next sections describe the data and method employed to avoid the issues that undermine prior research and take up the question of the relationship between economic inequality and nonviolent protest.

\section{Data}

To test whether and how economic inequality affects individuals' propensity to engage in nonviolent protest, I combine cross-national survey data on protest collected in the four waves of the European Social Survey (ESS) conducted between 2002 and 2009 with data on inequality from the Standardized World Income Inequality Database (SWIID). The resulting dataset includes over 100,000 respondents in more than 75 country-year contexts in 25 different European democracies.

Measuring Protest. As noted above, nonviolent political protest can take many different forms. The ESS includes questions regarding three of the most important nonviolent protest activities: signing petitions, boycotting products, and participating in lawful demonstrations. Respondents were asked whether they had participated in each of these activities within the past twelve months. With its emphasis on participation over a fixed time period, this question minimizes the confusion of actual protest with mere expressions of willingness to protest; previous studies have noted the wide divergence between the two (e.g., Van Aelst and Walgrave 2001, 468).

In this sample, petitioning was the most common protest activity overall, with just over one in four respondents indicating that they had signed a petition in the previous year. But rates of petition signing varied considerably from country to country and year to year. Nearly half of respondents surveyed in Sweden in 2004 indicated they had recently signed a petition, the highest observed rate of participation in the sample, but only $4 \%$ of respondents had done so in the 2005 survey of Portugal. Boycotts were the form of protest in which Europeans engaged next most frequently: $18 \%$ of the ESS respondents examined here claimed to 
have boycotted certain products in an effort to improve their country or prevent things from going wrong. Here, too, those surveyed in Sweden were most active, with almost four in ten asked in 2008 saying that they had joined a boycott in the past year. And those in Portugal were again the least likely to engage in this form of protest, with less than $2 \%$ answering in the 2009 survey that they had done so. Taking part in lawful demonstrations was a much less common activity, with only about $7 \%$ of those surveyed answering that they had protested in this fashion. However, well over a third of respondents in Spain said that they had attended such demonstrations in 2004, when massive marches condemned the government's response to the Madrid train bombings. On the other hand, scarcely more than $1 \%$ of those surveyed in Hungary in 2005 answered that they had participated in a demonstration. To avoid the possibility that patterns in more common protest activities (such as signing petitions) could overwhelm differing patterns in less common ones (such as attending demonstrations) rather than combining these different forms of protest into a single measure, each of the three was examined separately.

Measuring Inequality. Data on economic inequality were drawn from the SWIID. Based on data from the Luxembourg Income Survey, the United Nations University's World Institute for Development Economics Research, and many other national and international sources, the SWIID maximizes the comparability of inequality data for the largest possible sample of countries and years (Solt 2009). ${ }^{2}$ I use the SWIID's Gini index of net income inequality, which describes the distribution of income across size-adjusted households after government taxes and transfers are taken into account. The Gini index has a theoretical range of 0 , meaning that an equal share of net income is received by each household, to 100, which means that all income goes to a single household. In the sample examined here, the lowest values of the Gini index were about 22.5, for example in Sweden and Denmark in 2002; the highest, about 36.5, were observed in Portugal in 2002 and 2005. Bivariate correlations between this measure of inequality and country-year averages of the protest variables described above are strongly negative for petitioning $(-.40, p<.001)$ and boycotting $(-.38, p<.001)$ but are indistinguishable from zero for demonstrating $(.05, p=.66)$.

Measuring Income. The relative power theory, grievance theory, and resource theory all point to individuals' relative incomes - that is, where in the distribution their incomes are located - as important to the 
effect of the shape of the income distribution has on their participation in nonviolent protests. The measure of income used here is the quintile of household income. To facilitate interpretation, this five-point income variable is centered so that the median quintile is coded as 0 , the poorest quintile is coded as -2 , and the richest quintile is coded as $2 .^{3}$

Control Variables. A number of other aspects of context and individual characteristics may be expected to affect participation in nonviolent protests. First, the age of a democracy is thought to be important. Older democracies, according to this argument, have developed institutional channels for responding to protesters' demands, while new democracies are still working to establish these channels; as a result of these differences in the opportunity structure, people should be less likely to protest in new democracies than in older ones (Dubrow, Slomczynski, and Tomescu-Dubrow 2008, 37). New democracies are operationalized here as those less than two decades old.

Also, as alluded to above, the particular institutional arrangements of a democracy may be expected to affect the likelihood that protests succeed and, by shaping the political opportunity structure in this way, either foment or dissuade protest activity. In particular, the formal division of power found in presidential systems and the broader geographic distribution of power found in federal systems are thought to yield more points of access to the policymaking process for potential protesters and so encourage protest activity (see Kriesi et al. 1995, 28-29; Vráblíková 2014). Bicameral legislatures might similarly be expected to spur protest by providing an additional, distinct audience to which appeals can be directed (cf., Druckman and Thies 2002).

More proportional electoral systems are known to yield governments that are more representative, consensual, and effective (Lijphart 1999; Powell 2000). When votes are more faithfully translated into political influence, it should therefore be expected that fewer citizens will feel the need to avail themselves of the alternative means of expressing their preferences provided by nonviolent protest activities. The proportionality of the electoral system is measured here by the effective district magnitude, the average number of seats elected per district adjusted to account for minimum thresholds and upper tiers that affect how votes are translated into seats (see Taagepera and Shugart 1989). 
Party pluralism is another, related explanation offered for variation in protest activity across countries and over time. More parties in the legislature generally make coalition formation and maintenance more difficult, so protest may be more effective in generating desired policy changes (see Kriesi et al. 1995, 30-31). The measure of pluralism used is the effective number of parliamentary parties, that is, a count of the number of parties in the legislature that weighs each by its share of seats.

Whether individuals engage in protest may depend on whether they have immediate (or recent) opportunities to express their preferences through the ballot box. A dummy variable indicating election years was therefore included in the analyses.

Beyond institutional characteristics, higher levels of economic development have been argued to create environments conducive to nonviolent protest by bringing a dense infrastructure for communication among the potential protesters as well as vibrant media that increase awareness of protest activity among the broader public (Dalton, Van Sickle, and Weldon 2010, 4-5). Economic development is operationalized here as GDP per capita adjusted for differences in purchasing power, with data drawn from the Penn World Tables (Heston, Summers, and Aten 2011). Further, labor unions work to politically organize and mobilize not only their members but also the rest of their societies (Radcliff and Davis 2000), so the union density of a country's workforce might be expected to have a positive relationship with protest activity. On the other hand, stronger unions are better situated to negotiate on behalf of their constituencies through institutionalized bargaining, which may make people less likely to resort to protest where union density is higher (see, e.g., Wallace and Jenkins 1995, 53).

Previous studies of protest have pointed to a number of individual characteristics as important determinants of participation in protest activities. The seminal work of Marsh and Kaase $(1979,130)$ found that people who were younger, better educated, and male were more inclined to engage in protest. Subsequent works have documented that women have become more likely to protest than men (e.g., Marien, Hooghe, and Quintelier 2010) and also that the employed and union members are more likely to join protests than others (e.g., Van Aelst and Walgrave 2001). To account for individual differences in the propensity to protest, control variables were included for the ESS respondents' age, years of education, gender, marital status, 
employment status, and union membership.

It is worth noting that, although a number of individual attitudes such as political interest or 'emancipative values' have been linked to the propensity to engage in nonviolent protest (see, e.g., Welzel and Deutsch 2012), these are not appropriate to include as controls in this analysis. According to the relative power theory, such attitudes are themselves caused by economic inequality (see, e.g. Solt 2008, 2012). Controlling for variables that are causally downstream from an independent variable, as Gelman and Hill (2007) point out, "messes up" the estimates of that independent variable's effect on the dependent variable.

\section{Method}

Assessing the causes of differing rates of participation in nonviolent protest requires a method that distinguishes between independent variables that differ across individuals (such as age), those that vary only across countries and over time (like income inequality), and those that vary only across countries and not over time in this dataset (such as bicameralism). Neglecting this three-level nature of the data violates the assumption of independent errors (see Steenbergen and Jones 2002). For this reason, the analysis proceeds using an explicitly multilevel model. For individual $i$ in country-year $j$ in country $k$, the equation for the model to be estimated is:

$$
\begin{aligned}
& \text { Protest }_{i j k}=\gamma_{000}+\gamma_{100} \text { Age }_{i j k}+\gamma_{200} \text { Education }_{i j k} \\
& +\gamma_{300} \text { Female }_{i j k}+\gamma_{400} \text { Married }_{i j k}+\gamma_{500} \text { Employed }_{i j k} \\
& +\gamma_{600} \text { Union Member } \text { Me }_{i j k}+\gamma_{700} \text { Income Quintile }_{i j k} \\
& +\gamma_{010} \text { Inequality }_{j k}+\gamma_{710} \text { Inequality }_{j k} \times \text { Income }_{i j k} \\
& +\gamma_{020} \text { GDP } / \text { Capita }_{j k}+\gamma_{030}{\text { Election } \text { Year }_{j k}} \\
& +\gamma_{040} \text { Party Pluralism }_{j k}+\gamma_{050} \text { Union Density }_{j k} \\
& +\gamma_{001} \text { Presidential }_{k}+\gamma_{002} \text { Federal }_{k}+\gamma_{003} \text { Bicameral }_{k} \\
& +\gamma_{004} \text { District Magnitude }{ }_{k}+\gamma_{005} \text { New Democracy } \\
& +r_{0 j k}+r_{7 j k} \text { Income }_{i j k}+u_{00 k}
\end{aligned}
$$

In addition to including predictors at all three levels of analysis, each with a coefficient $\gamma$, this multilevel model includes both varying intercepts and varying slopes (see Gelman and Hill 2007). That is, first, that 
through separate error terms for each country $\left(u_{00 k}\right)$ and country-year $\left(r_{0 j k}\right)$, it allows the average level of peaceful protest within these units to vary to reflect circumstances in a particular country or year that remain outside of the model. ${ }^{4}$ And second, it includes a separate error term for the coefficient of household income quintile $\left(r_{6 j k}\right)$ and so allows the estimated effect of this variable to vary from one country-year context to the next. Because each of the three measures of protest participation are dichotomous, the model was estimated using logistic regression. ${ }^{5}$ The analyses were conducted using HLM 6.0 software.

A last methodological concern regards the interaction of the context of inequality with the individual's income: such interaction terms require particular care in interpretation (e.g., Braumoeller 2004). The marginal effect of inequality on the protest participation of people with a given income is calculated as the partial derivative of Equation 1 with respect to inequality: $\frac{\partial \text { Protest }_{i j k}}{\partial \text { Inequality }_{j k}}=\gamma_{010}+\gamma_{710}$ Income $_{i j k}$. That is, the estimated effect on an individual's protest participation of a change in inequality equals the sum of the estimated coefficient of inequality, $\gamma_{010}$, and the product of the coefficient of the interaction between inequality and income, $\gamma_{710}$, and the individual's income. The relative power, grievance, and resource theories each offer distinctly different predictions for these coefficients. Recall that the relative power theory maintains that economic inequality should depress nonviolent protest participation among people of all incomes, but that this negative effect will be smaller for those with higher incomes than for those with lower incomes. Put in the terms of Equation 1, it predicts that the coefficient of economic inequality, $\gamma_{010}$, will be negative and that the interaction between inequality and income, $\gamma_{710}$, will be positive. Further, it predicts that the the product of $\gamma_{710}$ and income quintile will have a smaller absolute value than $\gamma_{010}$, that is, that their sum will always be less than zero. Resource theory suggests that inequality will reduce protest among poorer individuals but increase it among richer ones. This hypothesis yields predictions that are similar in sign to those of the relative power theory but different in magnitude: the coefficient of inequality, $\gamma_{010}$, will be negative and the interaction term, $\gamma_{710}$, will be positive, but absolute value of the product of $\gamma_{710}$ and income quintile will be larger than $\gamma_{010}$ for the richest income quintiles. Finally, the grievance theory contends that inequality should make poorer people more likely to protest and richer ones less so. Its predictions are the exact opposite of the resource theory. If the grievance theory is correct, $\gamma_{010}$, will be positive and the 
interaction between inequality and income, $\gamma_{710}$, will be strongly negative so that inequality has a positive effect on the protest participation of those in poorer income quintiles but a negative effect on that of those in richer quintiles.

\section{Results}

Figure 1 displays the results of these analyses. ${ }^{6}$ The dots represent the coefficient estimates, and the whiskers trace the $95 \%$ confidence intervals (see Kastellec and Leoni 2007). To facilitate comparison across the predictors, the coefficients of the ordinal and continuous independent variables were rescaled: the unstandardized coefficients were multiplied by twice the standard deviation of the variable. Rescaling in this way makes the resulting coefficient estimates represent the expected change in the logged odds of the dependent variable occurring for a change in the independent variable from one standard deviation below to one standard deviation above its mean and so makes these coefficients directly comparable to those for the dichotomous independent variables (see Gelman 2008). The coefficients for income inequality in all three models are negative and statistically significant. Those for the interaction of inequality and individual household income quintile are all positive and reach statistical significance for boycotting and demonstrating; the estimated effect of inequality remains negative for individuals of even the richest quintile, but it is smaller for richer individuals than it is for poorer ones. These results support only the relative power theory of protest participation.

\section{[Figure 1 about here.]}

Although rescaling allows direct comparison of the relative magnitude of the independent variables, because all three measures of peaceful protest are dichotomous, the coefficients depicted in Figure 1 are measured in logits, and so their absolute magnitudes remain difficult to assess. For this reason, I calculated the predicted probability of reporting having participated in each of these forms of protest for individuals in each income quintile over the full observed range of income inequality when all other variables are held constant at their median values. Figure 2 depicts the results for those in the richest, median, and poorest income quintiles. For otherwise typical people in otherwise typical contexts with incomes in the richest 
quintile, income inequality has no statistically significant effects on the probability of taking part in these three protest activities: the top row of graphs shows that the estimates are negative but small relative to their associated uncertainty. The protest activity of poorer individuals, on the other hand, is substantially reduced as economic inequality rises.

\section{[Figure 2 about here.]}

The first column of graphs in Figure 2 shows the predicted probabilities of signing a petition, the most common form of protest across Europe, given the assumptions described above. For individuals with household incomes in their country's median quintile at the time of the survey, the predicted probability of signing a petition falls by 10 percentage points, with a $95 \%$ confidence interval of plus or minus 9 points. ${ }^{7}$ The magnitude of the decline increases somewhat as income falls: people in the poorest quintile of household income are $12 \pm 10$ percentage points less likely to sign a petition at the highest observed levels of income inequality than at the lowest observed levels. For those with median incomes or below, the effect of income inequality on participation in petition drives was similar in magnitude to the difference between those who had finished college and otherwise-similar high school dropouts. With the other variables fixed at median values, those with sixteen or more years of education were $27 \pm 8$ percentage points more likely to protest in this way than those without any formal education, and the oldest respondents were $13 \pm 6$ points less likely to do so than eighteen-year-olds. Compared to those living in long-established democracies, people in new democracies were $15 \pm 10$ points less likely to sign petitions. Party pluralism was estimated to increase petition signing by as much as $18 \pm 11$ percentage points under these assumptions, but the proportionality of the electoral system was found to reduce it by up to $17 \pm 12$ points: given the well-understood positive relationship between these two variables (see, e.g., Taagepera and Shugart 1989), these effects can reasonably be expected to largely counteract each other in most cases. Those belonging to a union were $8 \pm 2$ points more likely to sign a petition than those who were not. Women (by $4 \pm 2$ points) and the employed ( $2 \pm 1$ points) were also estimated to be more likely to sign petitions, but only by relatively small amounts. Petition signing was slightly less common in years when elections were held (by $3 \pm 2$ points) than at other times. The estimated effects of presidentialism, federalism, differences in economic development, and union density on 
petition activity could not be distinguished from zero.

The predicted probabilities of boycotting a product are displayed in the center column of Figure 2. As with signing petitions, the effect of income inequality on joining boycotts for people in the richest household income quintile did not reach statistical significance. However, inequality has important effects on the probability of boycotting a product for otherwise typical individuals in every other quintile: by $10 \pm 9$ percentage points in the second richest quintile, by $12 \pm 9$ points in the median quintile, by $13 \pm 9$ points in the second poorest quintile, and by $14 \pm 9$ points in the poorest quintile. Only education and electoral proportionality had larger maximum effects on boycott participation. Those with sixteen years of education were $23 \pm 7$ points more likely to boycott a product than those with no schooling. Compared to those living in countries with single member districts, people whose electoral systems were the most proportional were $16 \pm 8$ points less likely to boycott. People in new democracies were also less likely to participate in boycotts, by $11 \pm 7$ points. Union

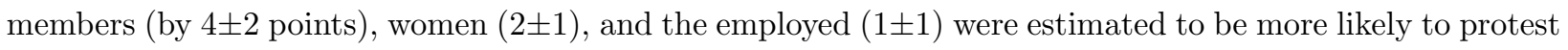
through boycotts than others.

Demonstration activity, the most demanding form of protest behavior, is depicted in the third column of Figure 2. Income inequality is an important predictor of demonstrating for those in the median quintile of household income and below. In the median income quintile, for otherwise median characteristics, the probability of attending a lawful demonstration at the lowest observed level of income inequality was estimated to be $7 \pm 2 \%$, but at the highest observed level of inequality, this probability declines by nearly half to just $4 \pm 2 \%$, a difference of $3 \pm 3$ percentage points. This difference was larger, $4 \pm 3$ points, for poorer individuals. The most educated were predicted to be $7 \pm 2$ points more likely to participate in lawful demonstrations than the least educated, and the oldest were $6 \pm 2$ points less likely to do so than the youngest adults. As was the case for the other forms of nonviolent protest examined here, more proportional electoral systems reduced demonstration activity, by $6 \pm 2$ points for typical people in otherwise typical contexts. Those in newer democracies were less likely to demonstrate by $4 \pm 2$ points. Union density decreased the probability of demonstrating by as much as $4 \pm 3$ points, but union members were estimated to be $4 \pm 1$ points more likely

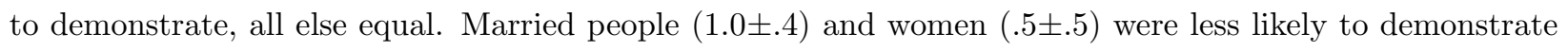


by statistically significant but relatively small amounts according to these results.

\section{Conclusion}

Across the European democracies since the beginning of the twenty-first century, higher levels of income inequality predict lower levels of participation in nonviolent protest activities, especially for those with lower incomes. The analyses presented above indicate that, for people in the bottom $60 \%$ of household income, more inequality predicts significantly lower probabilities of signing petitions and participating in demonstrations, and for all those in the bottom $80 \%$ of household income, more inequality predicts significantly lower probabilities of joining boycotts. Greater inequality does not predict more participation in any of these nonviolent protest activities for people of any income.

These results contradict the expectations of the grievance and resource theories of protest. More inequality does not enhance poorer individuals' sense of relative deprivation in ways that make them more likely to engage in protest, nor does it make richer individuals more likely to protest by providing them with more of the resources needed to do so. Instead, these results support only the relative power theory. By increasing the political power of richer individuals relative to poorer ones, greater inequality leads people of all but the highest income quintile to become less likely to participate in nonviolent protests. This pattern is similar to that found for electoral participation and other forms of political engagement (see Solt 2008, 2010), and it provides additional evidence that higher levels of economic inequality restrict the scope of democracy in ways that work to demobilize poorer people.

The findings of this paper also hint at the role of protest behavior within individuals' political repertoires. Some observers contend that such protest serves as an alternate means for citizens who find themselves shut out of the electoral process to press their demands (see, e.g., Lipsky 1968; Norris 2002). Others have argued that, most often, peaceful protest is a complement, rather than a substitute, to other political activities (see, e.g., Kaase and Marsh 1979; Oser and Shalev 2011). Although this question is not directly examined

here, the similarity of inequality's consequences for nonviolent protest and for more institutionalized forms of 
political engagement are suggestive. How rising economic inequality influences the range of political activities in which an individual participates would appear to be a promising avenue of future research. 


\section{Notes}

${ }^{1}$ Dalton, Van Sickle, and Weldon $(2010,14)$ also note in passing that they found that "the level of income inequality . . . had weak or insignificant correlations with protest."

${ }^{2}$ The principal advantage of the SWIID over other inequality datasets is its superior coverage: it is the only inequality dataset that provides full coverage of the countries and years in the ESS data. In comparison, Eurostat lacks inequality data for over a fourth of the sample examined here.

${ }^{3}$ Models including a series of four indicator variables in the place of this single five-point scale did not exhibit substantial nonlinearities in the effects of income across quintiles or yield substantively different conclusions, so the more straightforward linear measure of income is presented here.

${ }^{4}$ In this way, the model is similar to fixed-effect pooled time-series models, which include dummy variables for each country to capture country-specific effects.

${ }^{5}$ Although relatively small numbers of respondents indicated that they had participated in lawful demonstrations (slightly less than $7 \%$ of this sample), and logistic regression "can sharply underestimate the probability of rare events" King and Zeng $(2001,137)$, participation in demonstrations is not a rare event that requires a more sophisticated methodological treatment, at least not with these data. King and Zeng (2001) conducted Monte Carlo simulations of this bias and found that it declines in magnitude quickly as the frequency of the event grows and the number of observations increase. In fact, they found that when the event occurs with a probability of roughly $7 \%$, the maximum absolute difference in the predicted probability between logit and specialized rare events techniques falls from over 8 percentage points (i.e., more than the actual probability) when $N=100$ to less than 0.9 percentage points when $N=20,000$. As there are actually more than seven times that many observations at the relevant level in these data, the downward bias resulting from using logistic regression is negligible.

${ }^{6}$ The regression coefficients are also presented as a table in Appendix B.

${ }^{7}$ The estimated effects on the predicted probability for people in the second highest household income quintile, like those of the richest, are not distinguishable from zero when the other included variables are fixed at median values. 


\section{References}

Balme, Richard, and Didier Chabanet. 2008. European Governance and Democracy: Power and Protest in the EU. Lanham, MD: Rowman \& Littlefield.

Boix, Carles. 2008. "Economic Roots of Civil Wars and Revolutions in the Contemporary World." World Politics 60(3):390-437.

Braumoeller, Bear F. 2004. "Hypothesis Testing and Multiplicative Interaction Terms." International Organization 58(4):807-820.

Dalton, Russell, Alix Van Sickle, and Steven Weldon. 2010. "The Individual-Institutional Nexus of Protest Behaviour." British Journal of Political Science 40(1):51-73.

Druckman, James N., and Michael F. Thies. 2002. "The Importance of Concurrence: The Impact of Bicameralism on Government Formation and Duration." American Journal of Political Science 46(4):760-771.

Dubrow, Joshua Kjerulf, Kazimierz M. Slomczynski, and Irina Tomescu-Dubrow. 2008. "Effects of Democracy and Inequality on Soft Political Protest in Europe: Exploring the European Social Survey Data." International Journal of Sociology 38(3):36-51.

Gelman, Andrew. 2008. "Scaling Regression Inputs by Dividing by Two Standard Deviations." Statistics in Medicine 27:2865-2873.

Gelman, Andrew, and Jennifer Hill. 2007. Data Analysis Using Regression and Multilevel/Hierarchical Models. Cambridge: Cambridge University Press.

Goodin, Robert, and John Dryzek. 1980. "Rational Participation: The Politics of Relative Power." British Journal of Political Science 10(3):273-292.

Gurr, Ted Robert. 1970. Why Men Rebel. Princeton: Princeton University Press.

Heston, Alan, Robert Summers, and Bettina Aten. 2011. "Penn World Table Version 7.0." Center for International Comparisons of Production, Income, and Prices, University of Pennsylvania. 
Iversen, Torben, and David Soskice. 2006. "Electoral Institutions and the Politics of Coalitions: Why Some Democracies Redistribute More Than Others." American Political Science Review 100(2):165-181.

Kaase, Max, and Alan Marsh. 1979. Political Action Repertory: Changes Over Time and a New Typology. In Political Action: Mass Participation in Five Western Democracies, ed. Samuel H. Barnes, and Max Kaase. Sage Publications pp. 137-166.

Kastellec, Jonathan P., and Eduardo L. Leoni. 2007. "Using Graphs Instead of Tables in Political Science." Perspectives on Politics 5(4):755-771.

King, Gary, and Langche Zeng. 2001. "Logistic Regression in Rare Events Data." Political Analysis 9(2):137163.

Kriesi, Hanspeter, Ruud Koopmans, Jan Willem Duyvendak, and Marco G. Giugni. 1995. New Social Movements in Western Europe: A Comparative Analysis. London: University College of London Press.

Lijphart, Arend. 1999. Patterns of Democracy: Government Forms and Performance in Thirty-Six Countries. New Haven: Yale University Press.

Lipsky, Michael. 1968. "Protest as a Political Resource." American Political Science Review 62(4):1144-1158.

Marien, Sofie, Marc Hooghe, and Ellen Quintelier. 2010. "Inequalities in Non-Institutionalized Forms of Political Participation: A Multilevel Analysis for 25 Countries." Political Studies 58(1):187-213.

Marsh, Alan, and Max Kaase. 1979. Background of Political Action. In Political Action: Mass Participation in Five Western Democracies, ed. Samuel H. Barnes, and Max Kaase. Beverly Hills: Sage Publications pp. $97-136$.

Nollert, Michael. 1995. Neocorporatism and Political Protest in the Western Democracies: A Cross-National Analysis. In The Politics of Social Protest: Comparative Perspectives on States and Social Movements, ed. J. Craig Jenkins, and Bert Klandermans. London: University College of London Press pp. 68-81. 
Norris, Pippa. 2002. Democratic Phoenix: Reinventing Political Activism. Cambridge: Cambridge University Press.

Oser, Jennifer, and Michael Shalev. 2011. "Examining the Participatory Expansion Hypothesis: The United States in Comparative Perspective." Paper presented at the Annual Meeting of the American Political Science Association, Seattle, WA.

Powell, G. Bingham, Jr. 2000. Elections as Instruments of Democracy. New Haven: Yale University Press.

Radcliff, Benjamin, and Patricia Davis. 2000. "Labor Organization and Electoral Participation in Industrial Democracies." American Journal of Political Science 44(1):132-141.

Solt, Frederick. 2008. "Economic Inequality and Democratic Political Engagement." American Journal of Political Science 52(1):48-60.

Solt, Frederick. 2009. "Standardizing the World Income Inequality Database." Social Science Quarterly 90(2):231-242. SWIID Version 3.1, December 2011.

Solt, Frederick. 2010. "Does Economic Inequality Depress Electoral Participation? Testing the Schattschneider Hypothesis." Political Behavior 32(2):285-301.

Solt, Frederick. 2012. "The Social Origins of Authoritarianism." Political Research Quarterly 65(4):703-713.

Steenbergen, Marco R., and Bradford S. Jones. 2002. "Modeling Multilevel Data Structures." American Journal of Political Science 46(1):218-237.

Taagepera, Rein, and Matthew S. Shugart. 1989. Seats and Votes: The Effects and Determinants of Electoral Systems. New Haven: Yale University Press.

Van Aelst, Peter, and Stefaan Walgrave. 2001. "Who is That (Wo)Man in the Street? From The Normalisation of Protest to the Normalisation of the Protester." European Journal of Political Research 39(4):461-486. 
Verba, Sidney, Kay Lehman Schlozman, and Henry E. Brady. 1995. Voice and Equality: Civic Voluntarism in American Politics. Cambridge: Harvard University Press.

Vráblíková, Kateřina. 2014. "How Context Matters? Mobilization, Political Opportunity Structures, and Nonelectoral Political Participation in Old and New Democracies." Comparative Political Studies $47(2): 203-229$.

Wallace, Michael, and J. Craig Jenkins. 1995. The New Class, Postindustrialism, and Neocorporatism: Three Images of Social Protest in the Western Democracies. In The Politics of Social Protest: Comparative Perspectives on States and Social Movements, ed. J. Craig Jenkins, and Bert Klandermans. London: University College of London Press pp. 48-57.

Welzel, Christian, and Franziska Deutsch. 2012. "Emancipative Values and Non-Violent Protest: The Importance of 'Ecological' Effects." British Journal of Political Science 42(2):465-479. 


\section{Figures}

Figure 1: Predicting Nonviolent Protest Activity

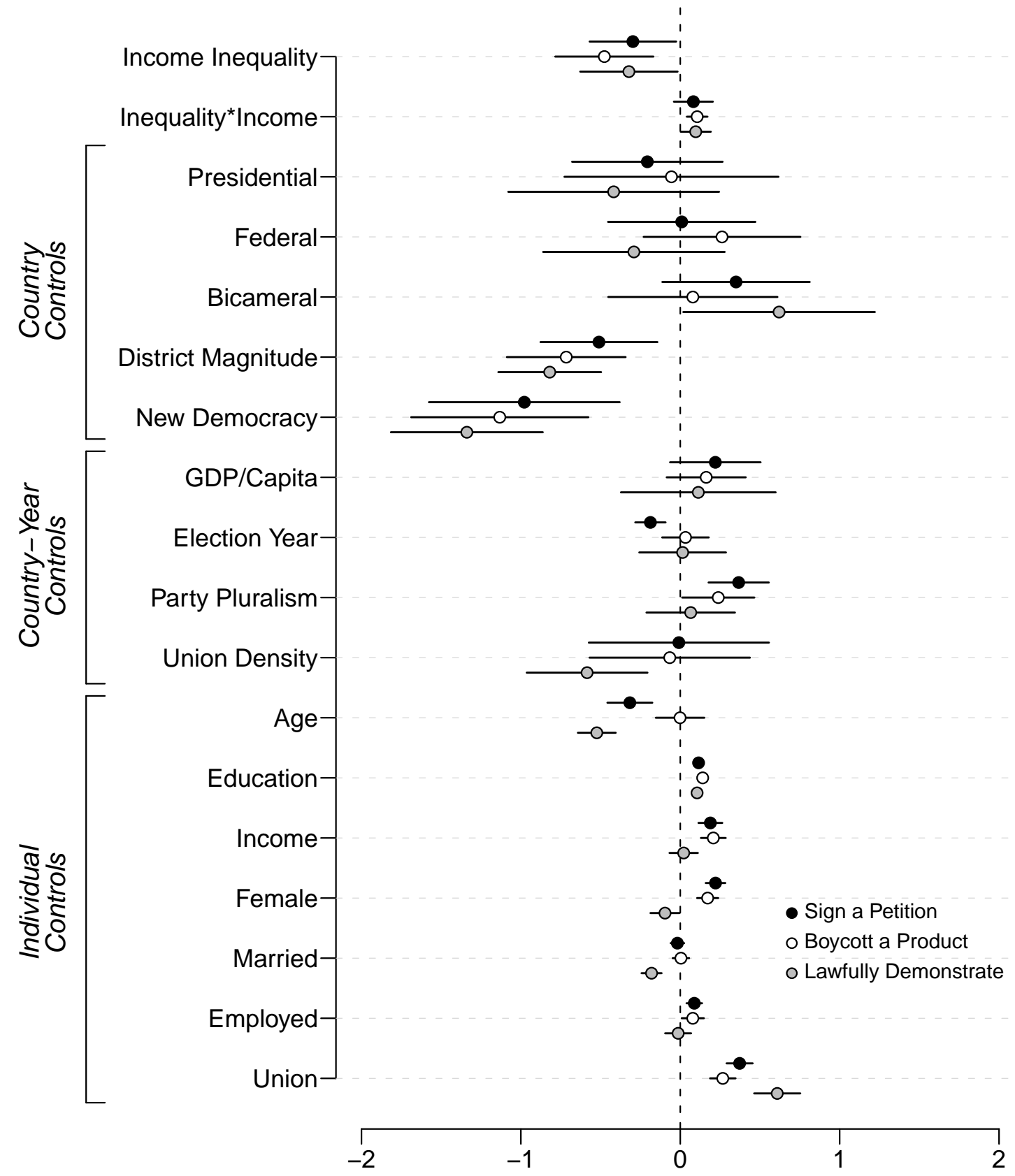

Note: The dots represent estimated change in the logged odds of the dependent variable occurring for a change of two standard deviations in the independent variable; the whiskers represent the $95 \%$ confidence intervals of these estimates. 
Figure 2: Predicted Probability of Participating in Protest by Income and Level of Inequality

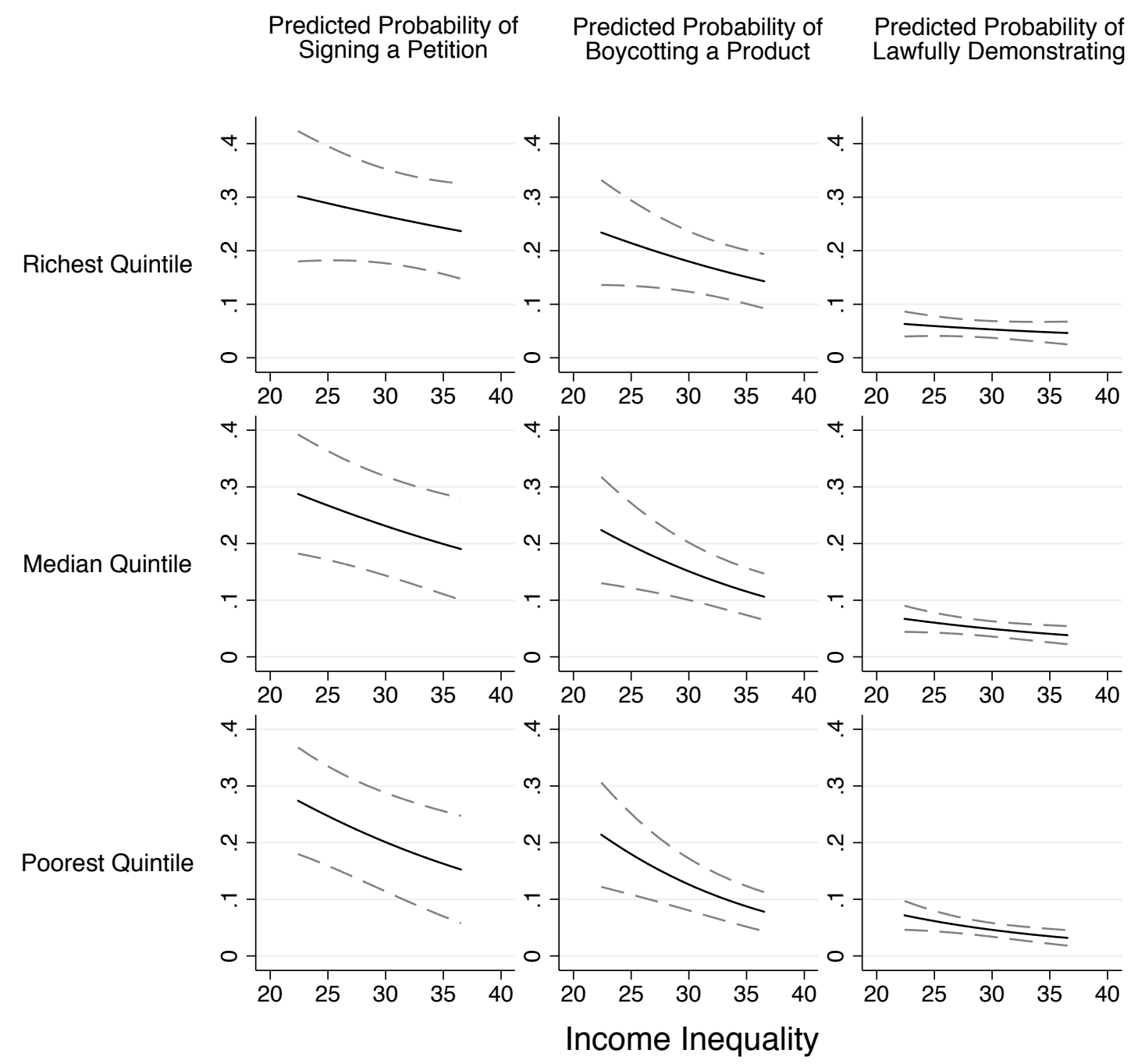

Source: Analyses presented in Figure 1; all other variables fixed at median values. 


\title{
Appendix
}

\section{A Included Countries and Years}

\author{
Austria 2003, 2005, 2007 \\ Belgium 2002, 2004, 2006, 2008 \\ Bulgaria 2006, 2009 \\ Cyprus 2006, 2008 \\ Czech Republic 2002, 2004, 2009 \\ Denmark 2002, 2004, 2006, 2008 \\ Estonia $\quad 2004,2007,2009$ \\ Finland 2002, 2004, 2006, 2008 \\ France 2003, 2005, 2006, 2008 \\ Germany 2003, 2004, 2006, 2008 \\ Greece 2003, 2005, 2009 \\ Hungary $\quad 2002,2005,2006,2009$ \\ Ireland 2003, 2005, 2007, 2009 \\ Italy 2003, 2006 \\ Luxembourg 2003, 2004 \\ Netherlands 2002, 2004, 2006, 2008 \\ Norway 2002, 2004, 2006, 2008 \\ Poland 2002, 2004, 2006, 2008 \\ Portugal 2002, 2005, 2007, 2009 \\ Slovak Republic 2004, 2006, 2008 \\ Slovenia $\quad 2002,2004,2006,2008$ \\ Spain $\quad 2002,2004,2006,2008$ \\ Sweden 2002, 2004, 2006, 2008 \\ Switzerland 2002, 2004, 2006, 2008 \\ United Kingdom 2002, 2004, 2006, 2008 \\ Source: European Social Survey Cumulative File, ESS 1-4 (2011). Data file edition 1.0. Norwegian Social \\ Science Data Services, Norway.
}




\section{B Logistic Regression Coefficients}

\begin{tabular}{|c|c|c|c|}
\hline \multirow{2}{*}{ Independent Variable } & Sign a Petition & Boycott a Product & Lawfully Demonstrate \\
\hline & Estimate (Std. Error) & Estimate (Std. Error) & Estimate (Std. Error) \\
\hline Income Inequality & $-.039 *(.018)$ & $-.063^{*}(.021)$ & $-.042^{*}(.021)$ \\
\hline Inequality $\times$ Income Quintile & $.008(.006)$ & $.010 *(.003)$ & $.009 *(.005)$ \\
\hline \multicolumn{4}{|l|}{ Country Controls } \\
\hline Presidential & $-.202 \quad(.242)$ & $-.063(.354)$ & $-.419 \quad(.342)$ \\
\hline Federal & $.006 \quad(.231)$ & $.255 \quad(.252)$ & $-.297 \quad(.298)$ \\
\hline Bicameral & $.343 \quad(.242)$ & $.085 \quad(.268)$ & $.628^{*}(.310)$ \\
\hline District Magnitude & $-.016^{*}(.006)$ & $-.022 *(.006)$ & $-.025^{*}(.005)$ \\
\hline New Democracy & $-.984^{*}(.313)$ & $-1.134^{*}(.284)$ & $-1.332^{*}(.245)$ \\
\hline \multicolumn{4}{|l|}{ Country-Year Controls } \\
\hline GDP/capita & $.011 \quad(.007)$ & $.008 \quad(.006)$ & $.006 \quad(.013)$ \\
\hline Election Year & $-.186^{*}(.049)$ & $.032 \quad(.076)$ & $.014 \quad(.141)$ \\
\hline Party Pluralism & $.128 *(.034)$ & $.083 *(.039)$ & $.022 \quad(.050)$ \\
\hline Union Density & $>-.001 \quad(.007)$ & $-.001 \quad(.006)$ & $-.014^{*}(.005)$ \\
\hline \multicolumn{4}{|l|}{ Individual Controls } \\
\hline Age & $-.009 *(.002)$ & $>-.001 \quad(.002)$ & $-.015^{*}(.002)$ \\
\hline Years of Education & $.115^{*}(.010)$ & $.141 *(.006)$ & $.105^{*}(.008)$ \\
\hline Income Quintile & $-.141 \quad(.166)$ & $-.197 *(.0914)$ & $-.244 \quad(.134)$ \\
\hline Female & $.222 *(.031)$ & $.171^{*}(.035)$ & $-.096^{*}(.046)$ \\
\hline Married & $-.019(.021)$ & $.005 \quad(.026)$ & $-.181 *(.032)$ \\
\hline Employed & $.087^{*}(.025)$ & $.078^{*}(.035)$ & $-.012 \quad(.042)$ \\
\hline Union Member & $.372^{*}(.042)$ & $.268 *(.042)$ & $.610^{*}(.076)$ \\
\hline Constant & $-1.981^{*}(.724)$ & $-2.100^{*}(.850)$ & $-1.623 \quad(.984)$ \\
\hline \multicolumn{4}{|l|}{ Variance Components } \\
\hline Income Slope & $.007^{*}$ & $.003^{*}$ & $.008^{*}$ \\
\hline Country-Year Intercept & .023 & .030 & .063 \\
\hline Country Intercept & $.247^{*}$ & $.215^{*}$ & $.152^{*}$ \\
\hline Individuals & 112,688 & 112,705 & 112,945 \\
\hline Country-Years & 78 & 78 & 78 \\
\hline Countries & 25 & 25 & 25 \\
\hline
\end{tabular}

${ }^{*} p<.05$, two-tailed tests. Results presented in Figure 1; unstandardized coefficients, robust standard errors. 